\title{
Product Choice and Product Switching
}

Andrew B. Bernard, Stephen Redding and Peter K. Schott

November 2003 


\begin{abstract}
This paper develops a model of endogenous product selection by firms. The theory is motivated by new evidence we present on the importance of product switching by U.S. manufacturers. Two-thirds of continuing firms change their product mix every five years, and product switches involve more than $40 \%$ of firm output and almost half of existing products. The theoretical model incorporates heterogeneous firms, heterogeneous products, and ongoing entry and exit. In equilibrium, firm productivity is correlated with product fixed costs, with the most productive firms choosing to make the products with the highest fixed costs. Changes in market structure result in systematic patterns of firm entry/exit and product switching.
\end{abstract}

Keywords: heterogeneous firms, product differentiation, sunk costs, entry and exit

JEL Classification: L11, D21, L60

The Centre for Economic Performance is financed by the Economic and Social Research Council. This paper was produced as part of the Centre's Globalisation Programme.

\title{
Acknowledgements
}

We thank Jonathan Haskel, Marc Melitz, Danny Quah, and seminar participants at CEPR, Dartmouth, Penn State, and LSE for helpful comments. Andrew B. Bernard and Peter K. Schott gratefully acknowledge research support by the National Science Foundation. Stephen Redding gratefully acknowledges financial support from a Philip Leverhulme Prize. The research in this paper was conducted at the Center for Economic Studies. Research results and conclusions expressed are those of the authors and do not necessarily indicate concurrence by the Bureau of the Census or by the National Bureau of Economic Research. The paper has not undergone the review the Census Bureau gives its official publications. It has been screened to insure that no confidential data are revealed.

Andrew B. Bernard is Tuck School of Business at Dartmouth and National Bureau of Economic Research. Stephen Redding is London School of Economics and Centre for Economic Policy Research. Peter K. Schott is Yale School of Management and National Bureau of Economic Research

Authors addresses:

Andrew B. Bernard

Tuck School of Business at Dartmouth 100 Tuck Hall

Hanover

NH 03755

email: andrew.b.bernard@ dartmouth.edu
Stephen Redding

CEP and Department of Economics

London School of Economics

Houghton Street

London WC2A $2 \mathrm{AE}$

email: $\underline{\text { s.j.redding@1se.ac.uk }}$
Peter K. Schott

Yale School of Management

135 Prospect Street

New Haven

CT 06520

email: peter.schott@yale.edu

Published by

Centre for Economic Performance

London School of Economics and Political Science

Houghton Street

London WC2A $2 \mathrm{AE}$

All rights reserved. No part of this publication may be reproduced, stored in a retrieval system or transmitted in any form or by any means without the prior permission in writing of the publisher nor be issued to the public or circulated in any form other than that in which it is published.

Requests for permission to reproduce any article or part of the Working Paper should be sent to the editor at the above address.

(C) A. B. Bernard, S. Redding and P. K. Schott, submitted 2003

ISBN 0753016729

Individual copy price: $£ 5$ 


\section{Introduction}

The choice of which product to make is a fundamental decision by a firm. Despite this, most theoretical models of firm behavior take product choicel by thelfirm as given, or treat entry into a product market ttolbel the same as the decision to create a firm. Similarly, there is no systematic evidence on the importance of product switching for the firm or on the scope of product switching across industries.

This paper models product choice by heterogeneous firms. The theory is motivated by a new set of stylized facts where we document the importance of product switching across U.S. manufacturing firms. Product switching, i.e. the addition or deletion of a product from the firm's output mix, is a widespread activity. More than two thirds of continuing U.S. manufacturing firms alter their product mix over a five year period. For firms, adding or dropping a product is an important event, affecting more than one third of current products and current output. Over half of all product additions also expand the mix of industries produced by the firm.

Our theoretical model incorporates heterogeneous firms, heterogeneous products, and ongoing entry and exit in general equilibrium. Firms choose which product to produce within an industry as well as whether to enter or exit the market. Products differ both in terms of how they are demanded and in their production techniques. Product choice is determined by an interaction between firm characteristics, product characteristics, and market conditions. Changes in market characteristics, production technologies, or consumer tastes are associated with changes in entry and exit rates, industry and product productivity, and product switching by firms.

We model firms as being heterogeneous in terms of their productivity and products as differing in terms of their fixed costs of production. In equilibrium, firm productivity is correlated with product choice, with the most productive firms endogenously choosing to make the products with the highest fixed costs. Both product choice and entry/exit decisions are endogenously determined by market structure.

Our framework builds on Melitz's (2002) dynamic industry model with heterogenous firms. We extend that model by introducing multiple products defined by their fixed and variable costs of production and their substitutability in consumption. Our framework incorporates endogenous firm entry and exit decisions and variation in firm productivity (as in Hopenhayn 
1992 and Jovanovic 1982); horizontal product differentiation and monopolistic competition (as in Krugman 1980); and endogenous product choice based on production technique or quality (as in Shaked and Sutton 1987 and Sutton 1998).

This paper concentrates on interactions of firm characteristics, product characteristics and market conditions as sources of product switching. However, product choice is not only interesting in its own right, but potentially has implications for the firm's decisions about investment, factor and material purchases, and pricing that lie beyond the scope of this paper. Similarly for the industry, we consider the relation of product choice by firms to market structure and productivity growth and leave unmodelled consequences for international trade and investment flows, returns to factors, and the nature of competition.

The remainder of the paper is structured as follows. Section 2 provides evidence on product switching by U.S. manufacturing firms from 1972-1997. Section 3 considers existing empirical and theoretical work on industries with heterogeneous firms and presents a non-technical overview of the theoretical model. In section 4 , we develop the model while section 5 solves for general equilibrium. A technical appendix at the end of the paper contains important derivations and proofs of the propositions. Section 6 examines the effects of changes in the model's parameters on firm-level choices and industry equilibrium. Section 7 concludes.

\section{Product Switching By U.S. Manufacturing Firms, 1972-1997}

In this section we provide the first complete view of product switching by U.S. manufacturing firms. ${ }^{1}$ We look at the importance of adding and

\footnotetext{
${ }^{1}$ Dunne, Roberts, and Samuelson (1988) use U.S. Census data from 1963-1982 to examine forms of entry into industries by firms. They find that just under half of all new entrants in an industry come from continuing firms, i.e. firms adding an industry. Their paper examines rates of (more aggregate) industry entry and exit and subsequent performance by different types of entrants rather than the extent and importance of product additions and deletions by firms. Streitweiser (1992) uses U.S. Census data to describe the number of products (SIC5) produced by U.S. manufacturing plants during the period 1972-1982. Her focus is on the similarity of products produced at multiple product plants, not on product switching. Gollop and Monahan (1991) also use U.S. Census data to construct an index of firm diversification based on 5-digit products. They report increasing firm diversification and declining plant diversification within most 2-
} 
dropping products for the manufacturing sector a whole as well as for individual firms. We start by documenting the extent of this activity across firms in the U.S. manufacturing sector. Next, we consider the importance of product-switching at the firms themselves. Finally, we ask whether product switches are associated with significant changes in the firm's output mix.

Our data comes from the Censuses of Manufactures (CM) of the Longitudinal Research Database (LRD) of the U.S. Bureau of the Census starting in 1972 and conducted every fifth year through 1997. The sampling unit for the Census is a manufacturing establishment, or plant, and the sampling frame in each Census year includes information on inputs, output, and products on all establishments. We aggregate the plant-level data up to the enterprise, or firm, for all the results reported in this paper. Examining the product mix of the firm, rather than the plant, has several advantages: it is both the level at which decisions are made about products and it avoids a potential problem of a firm shuffling its existing mix of products across plants. From the Census, we construct firm characteristics including the total value of shipments, the number of products produced, total value of each product produced, and information on the births and deaths of firms.

In constructing our sample, we make several modifications to the basic data. We use information on all manufacturing establishments in the six Censuses. While the LRD does contain basic information on small plants (so-called Administrative records), we do not include them in this study due to the lack of information on products. We aggregate the establishment level data in the Censuses up to the level of the firm. All our results are based on firm-level statistics. On average we are left with 141,561 continuing firms in each year. ${ }^{2}$

We refer to a product as a unique five-digit category in the 1987 Standard Industrial Classification (SIC5). ${ }^{3}$ In Census years, plant output is

digit industries from 1963-1982 but do not address issues related to product switching. Bernard et al. (2002) provide evidence of U.S. manufacturing firms switching between industries in response to competition from low-wage countries.

${ }^{2}$ On average, over one third of manufacturing firms do not survive from one Census to the next. In these tables, we focus on product-switching at surviving, or continuing, firms. The subsequent theoretical model allows for firm failure as an outcome.

${ }^{3}$ We characterize where firms are located in product space and the extent of product 
recorded either at the five-digit or seven-digit SIC level of detail. Roughly 7,000 of the 15,000 seven-digit categories are recorded directly in the LRD, the rest are recorded at a five-digit level of aggregation. We aggregate seven-digit categories up to their five-digit 'product-class' to obtain a complete set of SIC5 products for all manufacturing firms. Our terminology differs slightly from that of the Census Bureau. We [Census] define four-digit categories as industries [industries] and five-digit categories as products [product classes].

Table 1: Average Share of US Manufacturing Firm Activity During 5-Year Census Period Intervals, 1972 to 1997

\begin{tabular}{|l|c|c|c|}
\hline \multirow{2}{*}{ Type of Firm } & \multicolumn{3}{|c|}{ Percent of Firms } \\
\cline { 2 - 4 } & All Firms & $\begin{array}{c}\text { Single Product } \\
\text { Firms }\end{array}$ & $\begin{array}{c}\text { Multiple } \\
\text { Product Firms }\end{array}$ \\
\hline Firm takes no action & 31 & 47 & 11 \\
Firm drops products only & 13 & na & 31 \\
Firm adds products only & 12 & 15 & 8 \\
Firm both adds and drops products & 43 & 38 & 50 \\
\hline & \multicolumn{3}{|c|}{ Percent of Output } \\
\cline { 2 - 4 } Type of Firm & \multirow{2}{*}{ All Firms } & Single Product & Multiple \\
& 7 & Firms & Product Firms \\
\hline Firm takes no action & 8 & na & 3 \\
Firm drops products only & 5 & 21 & 3 \\
Firm adds products only & 81 & 29 & 86 \\
Firm both adds and drops products & & & \\
\hline
\end{tabular}

Note: Table displays average share of continuing US manufacturing firms engaging in each activity across five year intervals from 1972 to 1997 . Add and Drop refer to firms adding or dropping at least one five-digit SIC manufacturing 'product' during the five years between Censuses of Manufactures. The upper panel reports the distribution of firms while the lower panel reports the distribution of output. Results are reported for the full sample of firms as well as for single- and multiple-product firms separately. On average, there are roughly 140,000 firm observations in each Census year. "na" indicates not applicable: single product surviving firms cannot drop their only product and continue in business.

Product switching is a pervasive activity among U.S. manufacturing

switching using Standard Industrial Classification codes. This has a number of important advantages: firms report several SIC5 codes and we can explicitly observe the addition and deletion of products; also, SIC5 codes are typically chosen on the basis of distinct product characteristics and are more aggregated than varieties of the same product. See US Census (1996), http://www.census.gov/prod/2/manmin/mc92-r-1.pdf, for a complete list of SIC5 categories. 
firms. During a typical five year period, two thirds of continuing firms add or drop a (SIC5) product from their output mix. ${ }^{4}$ This activity is summarized in the first panel of Table 1, which reports a breakdown of product switching for continuing U.S. manufacturing firms. The numbers in the table refer to the average fraction of firms undertaking the activity described in the first column across five year Census intervals from 1972 to 1997. The numbers reported in all the tables are averages from 1972-1997, there is little variation across Censuses. We divide all continuing firms into one of four types: (a) those that leave their product mix unchanged, i.e. neither add nor drop a SIC5 product; (b) those that drop at least one product and do not add any; (c) those that add at least one product but do not remove an existing product from their output mix; and (d) firms that both add and drop at least one product. The first four rows of the table summarize these four mutually exclusive activities.

Every five years, $43 \%$ of continuing firms shuffle their product mix by both dropping and adding products (column 1 of Table 1). Dropping alone and adding alone are far less frequent events, occurring at $13 \%$ and $12 \%$ of firms respectively.

The second and third columns of Table 1 compare the activity of single versus multiple-product firms. Single-product firms are likely to leave their product mix unchanged $(47 \%)$ or change it completely by dropping their existing product and adding one or more new ones $(38 \%)$. Half of all multiple-product firms both add and drop products, while $31 \%$ of such firms narrow their product mix by dropping one or more products. On average $89 \%$ of continuing multiple-product firms alter their product mix during a five year period. These numbers clearly demonstrate that product-switching is widespread among U.S. manufacturers and that simultaneous additions to and deletions from the existing product mix are

\footnotetext{
${ }^{4} \mathrm{~A}$ product addition in the data can represent one of three general activities. The first, related to product innovation, is the creation of an entirely new good at an existing plant which is classified in an existing SIC5 category. The second is the start of production of an existing good, new to the firm but not to the market, also in an existing SIC5 category. Innovation of a new good can occur but not be captured as a product addition if it occurs in a SIC5 category where the firm is currently active. Finally, a product addition may represent the firm's acquisition of a plant that is producing one or more products new to the firm. The category of product additions through acquisitions accounts for fewer than $10 \%$ of all switches.
} 
frequent events.

While product-switching occurs at a large proportion of firms it is even more important in terms of output. The second panel of Table 1 shows the fraction of total output produced by the four firm types. More than $80 \%$ of total output is generated at firms that both add and drop products. Multi-product firms that are large in size are the most active in changing their product mix in both directions.

Table 2: Average Number of Products Produced, Added and Dropped Across 5-Year Intervals, 1972 to 1997

\begin{tabular}{|c|c|c|c|}
\hline Type of Firm & $\begin{array}{r}\text { Number of } \\
\text { Products } \\
\end{array}$ & $\begin{array}{r}\text { Number of } \\
\text { Adds } \\
\end{array}$ & $\begin{array}{r}\text { Number of } \\
\text { Drops } \\
\end{array}$ \\
\hline All Firms & 2.3 & 1.1 & 1.1 \\
\hline Single Product Firms & 1.0 & 0.8 & \\
\hline Multiple Product Firms & 4.0 & 1.4 & 2.0 \\
\hline \multicolumn{4}{|c|}{$\begin{array}{l}\text { Note: Table displays mean number of products produced by continuing } \\
\text { US manufacturing firms across Census of Manufacturing years 1972- } \\
\text { 1997. Adds and Drops refer to the number of five-digit SIC } \\
\text { manufacturing products added to or dropped from a firm's product mix } \\
\text { during the five years between censuses. Results are reported for the full } \\
\text { sample of firms as well as for single- and multiple-product firms } \\
\text { separately. }\end{array}$} \\
\hline
\end{tabular}

Product turnover among manufacturing firms is substantial and occurs at both single-product and multiple-product firms. Table 2 reveals that the average continuing U.S. manufacturing firm produces 2.3 products at the beginning of a five year period, and subsequently adds and drops almost half of its product mix (1.1 products). On average, single-product firms add products while on average multiple-product firms drop half their existing products ( 2 dropped out of 4 produced) and add 1.4 new products. ${ }^{5}$

The products that are added and dropped by switching multi-product firms account for a large fraction of firm output. ${ }^{6}$ On average, products that were added in the last five years account for $50 \%$ of current firm output by value. Products that will be dropped over the next five years represent $46 \%$ of current shipments, Table 3 . For the median firm, recently added products are $42 \%$ of shipments while products to be dropped are more than

\footnotetext{
${ }^{5}$ Over time from 1972-1997, there is no systematic change in the number of products produced by continuing plants, nor in the fraction of products added or dropped.

${ }^{6}$ Obviously, single-product firms that switch change all their output.
} 
Table 3: Average Share of Firm Output in Products Added and Dropped in Multi-Product Firms Across 5-Year Intervals, 1972 to 1997

\begin{tabular}{l|c|c|c|}
\hline Activity & $\begin{array}{c}\text { Number of } \\
\text { Firms }\end{array}$ & $\begin{array}{c}\text { Mean Share of } \\
\text { Firm Output }\end{array}$ & $\begin{array}{c}\text { Median* Share of } \\
\text { Firm Output }\end{array}$ \\
\hline Added Products & 150,854 & 50 & 42 \\
Dropped Products & 142,178 & 46 & 34 \\
\hline
\end{tabular} Notes: Table displays mean and median value of continuing US
manufacturing firm's added and dropped products as a percent of total firm
output. Products are five-digit SIC aggregates. Figures are based on all
adding and dropping behavior across five-year Census of Manufacturing
years 1972 to 1997. Because of Census disclosure rules, which prohibit the
reporting of an actual median, the reported median is the average of the 100
observations around the true median.

a third of output by value.

The previous facts demonstrate that product-switching is a widespread phenomenon in the U.S. manufacturing sector, occurring at more than two thirds of continuing firms that produce more than $90 \%$ of total output. In addition, the results reveal that a sizable fraction of products are turned over every five years and that these products represent a large share of existing firm output. However, there remains the possibility that such activity involves switches among products that are quite similar. For example, switches between Canned Fruits and Canned Vegetables, both of which are five-digit products in SIC 2033, are unlikely to indicate important economic changes at a firm (see Appendix A for further discussion of the data).

To identify whether firms are merely adding products that are similar in nature, we examine the fraction of added-products that extend the range of production of the firm across industries. ${ }^{7}$ We focus our attention on product additions in multi-product firms. The first column of Table 4 shows that $54 \%$ of all added products are outside existing four-digit (SIC4) industries produced by the firm. Furthermore, more than a third of all new products are in a new three digit (SIC3) industry while $17 \%$ of added products involve a new two digit (SIC2) industry. The second column of the same table reports similar percentages for firms. Of firms that add

\footnotetext{
${ }^{7}$ Almost all empirical work on U.S. manufacturing identifies an "industry" by its 4digit (SIC) classification.
} 
Table 4: Share of Product Additions Outside the Existing Industry Mix of the Firm, 1972 to 1997

\begin{tabular}{|c|c|c|c|}
\hline \multicolumn{4}{|c|}{ Product Additions and Changes in Firm Industry Mix } \\
\hline & (I) & & (II) \\
\hline $\begin{array}{c}\text { Share of added products in: } \\
\text { existing SIC4 industries } \\
\text { new SIC4 industries } \\
\text { new SIC3 industries } \\
\text { new SIC2 industries }\end{array}$ & $\begin{array}{l}46 \\
54 \\
35 \\
17\end{array}$ & $\begin{array}{l}\text { Share of firms adding a product(s) that: } \\
\text { do not add a SIC4 industry } \\
\text { add a new SIC4 industry } \\
\text { add a new SIC3 industry } \\
\text { add a new SIC2 industry }\end{array}$ & $\begin{array}{l}42 \\
58 \\
41 \\
22\end{array}$ \\
\hline $\begin{array}{l}\text { Notes: Table reports the exten } \\
\text { industries. The first column of } \\
\text { are outside of the firm's existin } \\
\text { industries. The second columr } \\
\text { digit SIC manufacturing produ } \\
\text { manufacturing industries. }\end{array}$ & & $\begin{array}{l}\text { s add products outside their existing } \\
\text { rts the share of added five-digit SIC } \\
\text { r-, three- and two-digit SIC manufac } \\
\text { ports the share of firms adding at le } \\
\text { xisting mix of four-, three- and two- }\end{array}$ & $\begin{array}{l}\text { ts tha } \\
\text { five- }\end{array}$ \\
\hline
\end{tabular}

one or more products, $58 \%$ also add a new four-digit industry, while $41 \%$ $(22 \%)$ add a new three (two) digit industry to the mix produced by the firm. These results confirm that product-switching involves substantial changes in industry composition and tends to move a firm well beyond its existing mix of industries.

This section has documented the extent and quantitative importance of product switching. The remainder of the paper develops a theoretical model that explicitly incorporates product switching, while also remaining consistent with existing empirical work emphasizing heterogeneous firm characteristics and continuing entry and exit. We develop a general equilibrium dynamic industry model that, for the first time, simultaneously explains these three phenomena.

\section{Many Firms and Multiple Products}

The facts in the previous section suggest that product choice at surviving firms should be added to the growing list of stylized facts about industry performance. From Dunne, Roberts, and Samuelson $(1988,1989)$ we know that there is substantial covariation in industry entry and exit rates, suggesting an important role for sunk costs of entry. From Dunne, Roberts and Samuelson (1988, 1989), Davis and Haltiwanger (1991), Bernard and Jensen (1995) and the survey by Bartelsman and Doms (2000), we know that there is an enormous amount of firm heterogeneity within narrowly 
classified industries and that firm characteristics, such as productivity, are correlated with exit/survival and entry into exporting.

A series of theoretical papers have built upon these stylized facts in modelling industry evolution and performance. Jovanovic (1982) and Hopenhayn (1992) incorporate firm heterogeneity in equilibrium industry models with covariation in entry and exit rates due to underlying variation in sunk costs. Both models, and Olley and Pakes (1996), have the feature that firms will exit when their productivity falls below an endogenously determined cutoff. Bernard et al (2003) and Yeaple (2002) model the interaction of firm heterogeneity and entry into exporting. Melitz (2002) adds imperfect competition to a version of Hopenhayn (1992), allowing for industry entry and exit rates to covary and for firm characteristics to matter for the decision to export.

Our theoretical model extends a version of the heterogeneous firm framework of Melitz (2002) and Hopenhayn (1992) to incorporate product choice by surviving firms. We explicitly build on existing links between theory and stylized facts about firm heterogeneity and industry exit and entry rates. The key contribution of our model is to allow firms to choose endogenously between distinct products. At the heart of the model lies an interaction between firm heterogeneity and product heterogeneity that shapes product choice and product switching.

The model portrays an industry with a number of distinct products each containing a continuum of horizontally differentiated varieties. ${ }^{8}$ The products are imperfect substitutes and have different production technologies, specifically the fixed and variable costs. Each firm chooses to produce a variety of one of the two products. In addition to product choice, the model incorporates firm births and deaths, imperfect competition, and firm heterogeneity.

The model allows us to examine how changes in market conditions affect product choice through the interaction of firm characteristics and product attributes. Endogenous product switching by firms affects industry productivity and firm profitability. For example, changes in the sunk cost of starting a firm (entry cost) affect the distribution of firm productivity and,

\footnotetext{
${ }^{8}$ The model is for any 'market' with a common sunk cost of entry. Given the evidence on the variation of sunk costs across industries we refer to the market as an industry with heterogeneous products.
} 
at the same, induce some firms to switch products. ${ }^{9}$

The demand structure of the model is quite simple. Representative consumers have a taste for both products and have a love of variety within each product. Products are less substitutable in consumption than are varieties. Each variety is produced with a single input, labor, and is subject to a fixed cost (repeated each period) and a constant variable cost. A key feature of the model is that the period-by-period fixed costs vary across products (but not across varieties within products). Variable costs are also identical for all varieties but may or may not differ across products. ${ }^{10}$ This provides a particularly tractable way of formalizing the more general idea that there are differences in production technologies across products.

One interpretation of the difference in fixed costs across products is that it captures a difference in physical capital intensity. Although labor is the sole factor of production in the model, the labor used in paying the product fixed cost can be thought of as labor set aside to build and, in subsequent periods, maintain a machine. Another interpretation is that the difference in fixed costs captures ongoing expenditures that allow one product to be a higher quality than another. In this case, since the variable cost of production can be thought of as an inverse measure of product quality, the high fixed cost product must be characterized by a lower variable cost of production (higher product quality). More generally, as noted above, we make no assumptions about the relative value of the variable cost of production for the two products.

For tractability, the theoretical work focuses on the case of a single industry whose two products enter directly into final consumption. It is relatively straightforward to introduce many industries. The framework

\footnotetext{
${ }^{9}$ While we focus on the interaction of firm and product characteristics in a dynamic industry setting, we recognize that there are a variety of additional reasons that firms may add or drop products. Classic treatments of product choice include Hotelling (1929), Chamberlain (1951) and Lancaster (1966). More formal treatments of horizontal differentiation and vertical differentiation include Dixit and Stiglitz (1977), Shaked and Sutton (1982, 1987) and Spence (1976), synthesized in Tirole (1988). Issues related to product choice can also be found in work on corporate diversification, mergers and divestitures, and evolving firm capabilities and factor accumulation. See, among others, Amihud and Baruch (1981), Bolton and Farrell (1990), Chandler (1990), Helfat and Raubitschek (2000), Milgrom and Roberts (1990), and Montgomery (1994).

${ }^{10}$ Yeaple (2002) allows technologies for producing varieties to vary in terms of both fixed and variable costs in a static, single-product model.
} 
can also be extended to allow for any number of products within the industry. These extensions merely complicate the analysis without changing the model's key insights. ${ }^{11}$

There is a large pool of ex-ante identical potential entrants into the industry. To enter the industry (and hence either product market within the industry), firms must pay a sunk cost of entry. Firms then observe their productivity, drawn from a common distribution. At this point each firm decides whether to produce or exit the market. Firms with low productivity draws immediately exit. If the firm decides to produce it chooses to manufacture either product 1 or product 2 depending on the relative profitability of each product for that firm given its observed productivity. All firms, regardless of the product they produce, face a common exogenous probability of death in every period which, for simplicity, is assumed not to depend on their productivity. ${ }^{12}$

The solution of the model depends on three key equilibrium conditions: the zero profit cutoff condition which identifies the lowest productivity firm that chooses to produce; the product indifference cutoff condition which identifies the productivity level at which a firm is exactly indifferent between producing either of the two products ${ }^{13}$; and the free entry condition which forces expected profits before entry to equal the sunk cost of entry and is driven by the existence of a competitive fringe.

In the next three sections, we introduce the theoretical model in further detail, characterize general equilibrium, and explore how firms' product choice and the distribution of productivity across firms responds to changes in the underlying parameters of the model.

\footnotetext{
${ }^{11}$ For simplicity, we assume that all products already exist, although new varieties are created when the number of producing firms increases.

${ }^{12}$ This assumption supports a particularly tractable model of product choice, entry/exit, and firm heterogeneity. See Hopenhayn (1992) for an analysis of industry dynamics where productivity affects the probability of firm death, but that abstracts from product choice.

${ }^{13}$ A firm with this productivity would be either the highest productivity firm in the low fixed cost good or the lowest productivity firm in the high fixed cost good.
} 


\section{Theoretical Model: Endogenous Product Choice and Industry Dynamics}

The preferences of a representative consumer are a nested CES function of consumption of varieties of two products:

$$
U=\left[a C_{1}^{\nu}+(1-a) C_{2}^{\nu}\right]^{1 / \nu} .
$$

where $C_{i}$ is a consumption index of a continuum of horizontally differentiated varieties $\omega$ in each product market $i$ :

$$
C_{i}=\left[\int_{\omega \in \Omega_{i}} q_{i}(\omega)^{\rho} d \omega\right]^{1 / \rho}
$$

and $\left\{\Omega_{i}\right\}$ is the mass (number) of available varieties in market $i$.

On the demand side, products are distinguished from varieties in terms of consumers' elasticity of substitution. The two products are imperfect

substitutes for one another, with elasticity $\psi=\frac{1}{1-\nu}>1$. Similarly, varieties of each product are imperfect substitutes, with elasticity $\sigma=\frac{1}{1-\rho}>1$. However, the elasticity of substitution between varieties of the same product is higher than that between different products: $\sigma>\psi>1$. The parameter $0<a<1$ is a demand-shifter, which captures the relative weight of the two products in the consumer's utility function.

The dual price index for each product is:

$$
P_{i}=\left[\int_{\omega \in \Omega_{i}} p_{i}(\omega)^{1-\sigma} d \omega\right]^{1 / 1-\sigma} .
$$

and expenditures over varieties of each product are given by:

$$
r_{i}(\omega)=R_{i}\left(\frac{p_{i}(\omega)}{P_{i}}\right)^{1-\sigma}=\alpha_{i}(\mathcal{P}) R\left(\frac{p_{i}(\omega)}{P_{i}}\right)^{1-\sigma}
$$

where $R=R_{1}+R_{2}=\int_{\omega \in \Omega_{1}} r_{1}(\omega) d \omega+\int_{\omega \in \Omega_{2}} r_{2}(\omega) d \omega$ is aggregate expenditure; $\mathcal{P}=P_{2} / P_{1}$ is the relative price of product 2 ; and $\alpha_{i}(\mathcal{P})=R_{i} / R$ is the share of expenditure devoted to product $i$. With CES utility, these expenditure shares are:

$$
\alpha_{1}(\mathcal{P})=\left[1+\left(\frac{1-a}{a}\right)^{\psi} \mathcal{P}^{1-\psi}\right]^{-1}, \quad \alpha_{2}(\mathcal{P})=1-\alpha_{1}(\mathcal{P})
$$




\subsection{Production}

Each of a continuum of firms produces a unique variety $\omega$ in one of the two product markets. Production requires one factor, labor, which is inelastically supplied at its aggregate level $L$, which also indexes the size of the economy.

As well as entering demand as imperfect substitutes, the two products have different production technologies. The fixed costs of production for the two products are given by $\left\{f_{1}, f_{2}\right\}$ where $f_{2}>f_{1}$. For firms of the same productivity, $\varphi, b_{i}$ is a parameter that indexes variable costs of production for product $i$ where $b_{i}>0$. The key distinction between products is that the second good is subject to a higher fixed cost of production. We allow the variable cost for product 2 to be either higher or lower than for product 1. Without loss of generality, we set $b_{1}=1$ and $b_{2}=b$, so that $b$ captures the relative value of the two products' variable costs.

Given firm productivity $\varphi$, labor used is a linear function of output $q$ : $l_{i}=f_{i}+\frac{b_{i} q_{i}}{\varphi}$. Profit maximization under imperfect competition yields the standard result that equilibrium prices are a constant mark-up over marginal cost,

$$
p_{i}(\varphi)=\left(\frac{\sigma}{\sigma-1}\right) \frac{w b_{i}}{\varphi} .
$$

We choose the wage as numeraire so that $w=1$. Equilibrium profits for the two products are thus,

$$
\begin{aligned}
& \pi_{i}(\varphi)=\left(\frac{\alpha_{i}(\mathcal{P}) R}{\sigma}\right)\left(P_{i} \rho \frac{\varphi}{b_{i}}\right)^{\sigma-1}-f_{i} \\
& \pi_{i}(\varphi)=\frac{r_{i}(\varphi)}{\sigma}-f_{i} .
\end{aligned}
$$

From firms' revenue functions, the ratio of revenues for any two firms producing the same product depends only on their relative productivities,

$$
\frac{r_{i}\left(\varphi^{\prime \prime}\right)}{r_{i}\left(\varphi^{\prime}\right)}=\left(\frac{\varphi^{\prime \prime}}{\varphi^{\prime}}\right)^{\sigma-1} .
$$

Comparing revenues for firms producing different products is comparably 
straightforward; the ratio of revenues is a function of their relative productivities and relative prices of the two products,

$$
\frac{r_{2}\left(\varphi^{\prime \prime}\right)}{r_{1}\left(\varphi^{\prime}\right)}=\left(\frac{1-\alpha_{1}(\mathcal{P})}{\alpha_{1}(\mathcal{P})}\right)\left[\left(\frac{\varphi^{\prime \prime}}{\varphi^{\prime}}\right) \mathcal{P} \frac{1}{b}\right]^{\sigma-1} .
$$

where we have used $b_{1}=1$ and $b_{2}=b$. These relationships are useful because they allow us to express the revenue earned by every firm in terms of the revenue earned by another firm with a particular level of productivity.

\subsection{Market Entry and Exit}

To produce a variety (of either product), firms must pay a common fixed entry cost, $f_{e}>0$, which is thereafter sunk. After paying the sunk cost, firms draw their productivity, $\varphi$, from a common distribution, $g(\varphi)$. Firm productivity remains fixed after entry, i.e. we assume there is no feedback from product choice to productivity. Upon entering, there is an exogenous probability of death each period, $\delta$, which we interpret as due to force majeure events beyond managers' control.

The value of a firm with productivity $\varphi$ is therefore,

$$
\begin{aligned}
v(\varphi) & =\max \left\{0, \sum_{t=0}^{\infty}(1-\delta)^{t} \pi_{1}(\varphi), \sum_{t=0}^{\infty}(1-\delta)^{t} \pi_{2}(\varphi)\right\} \\
& =\max \left\{0, \frac{1}{\delta} \pi_{1}(\varphi), \frac{1}{\delta} \pi_{2}(\varphi)\right\}
\end{aligned}
$$

\subsection{Endogenous Product Selection}

Firms decide which good to produce based upon their productivity, taking as given the aggregate price indices $\left\{P_{1}, P_{2}\right\}$. Firms with zero productivity have negative post-entry profits in both industries, with the loss greatest for the high fixed cost product 2 :

$$
\pi_{1}(0)=-f_{1}>\pi_{2}(0)=-f_{2} .
$$

A firm with productivity $\varphi$ will produce good $i$ if it brings positive profit, i.e. covers the fixed production cost $f_{i}$, and is more profitable than producing good $j$. For both goods to be produced in equilibrium, it is sufficient for $\pi_{1}(\varphi)>\pi_{2}(\varphi)>0$ for some values of $\varphi$ and $\pi_{2}(\varphi)>\pi_{1}(\varphi)>0$ 
for other values of $\varphi$. Via (11), these conditions require product 1 profits to increase with productivity $\left(\frac{d \pi_{1}(\varphi)}{d \varphi}>0\right)$ and for product 2 profits to increase faster than product 1 profits $\left(\frac{d \pi_{2}(\varphi)}{d \varphi}>\frac{d \pi_{1}(\varphi)}{d \varphi}\right)$ for at least a range of values for $\varphi$. The second of these conditions is met if and only if

$$
\frac{d \pi_{2} / d \varphi}{d \pi_{1} / d \varphi}=\left(\frac{1-a}{a}\right)^{\psi}\left(\frac{1}{b}\right)^{\sigma-1} \mathcal{P}^{\sigma-\psi}>1
$$

where we have used the expression for the CES expenditure share, $\alpha_{1}(\mathcal{P})$, from equation 5. This inequality does not depend on $\varphi$, but rather on relative prices and parameters of demand and technology.

Two profit curves meeting the conditions for both products to be produced are displayed in Figure 1. The curve for $\pi_{2}$ intersects $\pi_{1}$ from below in the region where positive profits are made. Firms with productivity below $\varphi^{*}$ exit immediately upon entering the market because their productivity is too low to earn positive profit in either product market. Firms with productivity between $\varphi^{*}$ and $\varphi^{* *}$ enter the low fixed cost product market while firms with productivity greater than $\varphi^{* *}$ enter the high fixed cost product market. ${ }^{14}$

Figure 1 provides intuition for two key equilibrium conditions that we use to solve the model. First, the zero profit cutoff condition determines the lowest level of productivity where product 1 is produced and is given by,

$$
\text { (ZP) } \quad \pi_{1}\left(\varphi^{*}\right)=0 .
$$

Second the product indifference cutoff condition determines the lowest level of productivity where product 2 is produced and is given by,

$$
\text { (PI) } \quad \pi_{2}\left(\varphi^{* *}\right)=\pi_{1}\left(\varphi^{* *}\right) .
$$

\subsection{Free Entry}

A third equilibrium condition, the free entry condition, equates expected firm value and entry costs and is driven by the assumed existence

\footnotetext{
${ }^{14}$ Of course, in order for both goods to be produced, we also require that the fixed costs of production are not large enough to exhaust the economy's entire supply of labor. This condition must be satisfied as $f_{1} \rightarrow 0$ and $f_{2} \rightarrow f_{1}$.
} 


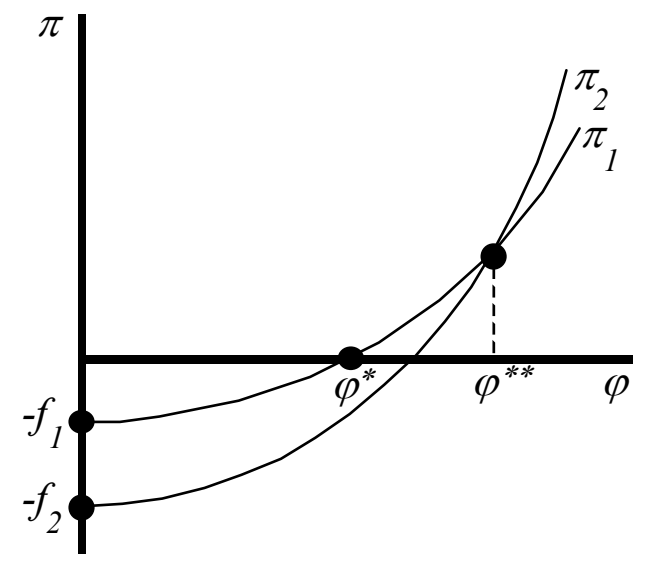

Figure 1: Profit Versus Productivity for the Two Products

of a competitive fringe of potential entrants. The expected value of a firm before entry, $v_{e}$, consists of two components. The first is the ex ante probability of producing product 1 times the expected profitability of producing this good until death. The second is the ex ante probability of producing product 2 times the expected profitability of producing this good until death. The cost of entry is equal to the sunk cost, $f_{e}$.

Using the definitions of the productivity cutoffs $\left(\varphi^{*}, \varphi^{* *}\right)$ above, the free entry condition is given by:

\section{(FE)}

$$
v_{e}=\frac{G\left(\varphi^{* *}\right)-G\left(\varphi^{*}\right)}{\delta} \bar{\pi}_{1}+\frac{1-G\left(\varphi^{* *}\right)}{\delta} \bar{\pi}_{2}=f_{e}
$$

where $\bar{\pi}_{1}$ and $\bar{\pi}_{2}$ are the expected or average profits from producing products 1 and 2, respectively. In Appendix B, we show that average profit in each market is equal to the profit earned by a firm with weighted average productivity: $\bar{\pi}_{1}=\pi_{1}(\widetilde{\varphi})$ and $\bar{\pi}_{2}=\pi_{2}(\widetilde{\widetilde{\varphi}})$, where $\widetilde{\varphi}$ and $\widetilde{\varphi}$ are the weighted average productivities of firms manufacturing products 1 and 2 In addition, weighted average productivity is a function of the two cutoff productivity levels, $\varphi^{*}$ and $\varphi^{* *}$. 


\subsection{Goods and Labor Markets}

The steady-state equilibrium is characterized by a constant mass of firms entering each period $M_{e}$, a constant mass $M_{1}$ producing product 1 , and a constant mass $M_{2}$ producing product 2 .

As shown in Appendix B, the product prices (PP) may be written as:

$$
\text { (PP) } \quad P_{1}=M_{1}^{1 / 1-\sigma} p_{1}(\widetilde{\varphi}), \quad P_{2}=M_{2}^{1 / 1-\sigma} p_{2}(\widetilde{\widetilde{\varphi}})
$$

where $p_{1}(\widetilde{\varphi})$ and $p_{2}(\widetilde{\widetilde{\varphi}})$ are the prices charged by a firm with weighted average productivity in each market.

A condition for steady-state equilibrium is that the mass of firms who enter and decide to produce a product equals the mass of current producers who die. Each period, a fraction $\delta$ of firms die. Thus, from the definitions of the productivity cutoffs above, these steady-state stability conditions (SC) are:

$$
\text { (SC) } \begin{aligned}
{\left[1-G\left(\varphi^{* *}\right)\right] M_{e} } & =\delta M_{2} \\
{\left[G\left(\varphi^{* *}\right)-G\left(\varphi^{*}\right)\right] M_{e} } & =\delta M_{1} .
\end{aligned}
$$

The labor market clearing condition (LM), expressed in value terms, requires that total labor payments equal the sum of payments to labor used in production and payments to labor used in the sunk costs of entry:

$$
\text { (LM) } \quad L=L_{p}+L_{e}
$$

where, since labor has been chosen for the numeraire, $w=1$.

\section{Equilibrium}

An equilibrium is referenced by the sextuple, $\left\{\varphi^{*}, \varphi^{* *}, P_{1}, P_{2}, R_{1}, R_{2}\right\}$ : all other endogenous variables may be written as functions of these variables. Equilibrium is fully characterized by the zero profit cutoff condition, the product indifference cutoff condition, the free entry condition, the steady-state stability condition (constant aggregate variables), the labor market clearing condition, and the product prices condition. 


\subsection{Product Supply and Relative Prices}

Combining the zero-profit $\mathbf{Z P}$ and product indifference PI conditions, we arrive at a product supply relationship between the productivity cutoffs $\left(\varphi^{* *} / \varphi^{*}\right)$ and relative prices $(\mathcal{P})$ that must hold when both goods are produced:

$$
\frac{\varphi^{* *}}{\varphi^{*}} \equiv \Lambda=\left[\frac{\left(\frac{f_{2}}{f_{1}}-1\right)}{\left[\left(\frac{1-a}{a}\right)^{\psi}\left(\frac{1}{b}\right)^{\sigma-1} \mathcal{P}^{\sigma-\psi}-1\right]}\right]^{1 /(\sigma-1)}
$$

where, in order for both goods to be produced, we require:

$$
\left(\frac{f_{2}}{f_{1}}-1\right)>\left[\left(\frac{1-a}{a}\right)^{\psi}\left(\frac{1}{b}\right)^{\sigma-1} \mathcal{P}^{\sigma-\psi}-1\right]>0 .
$$

As discussed below, relative prices adjust to ensure that this condition is satisfied in equilibrium. The middle inequality is just the requirement that profits for product 2 increase more rapidly in productivity than profits for product 1 (equation (12)), and ensures the right-hand side of (20) is positive. The first inequality incorporates information on fixed production costs, and ensures that profits for product $2, \pi_{2}$, intersect profits for product $1, \pi_{1}$, from below in the region where positive profits are made (Figure 1), so that the right-hand side of (20) is strictly greater than 1.

Equation (20) provides a downward sloping relationship between the productivity cutoffs, $\varphi^{* *} / \varphi^{*}$, and relative prices, $\mathcal{P}$. As the relative price of product 2 rises, this raises the profitability of product 2 relative to product 1 , inducing firms to switch from product 1 to product 2 , and leading to a fall in $\varphi^{* *}$ relative to $\varphi^{*}$.

\subsection{Product Demand and Relative Prices}

Combining the expression for product prices PP with the steady-state stability conditions $\mathbf{S C}$, we arrive at a product demand relationship between the productivity cutoffs $\left(\varphi^{* *} / \varphi^{*}\right)$ and relative prices $(\mathcal{P})$ :

$$
\left[\frac{\int_{\varphi^{*}}^{\varphi^{* *}} \varphi^{\sigma-1} g(\varphi) d \varphi}{\int_{\varphi^{* *}}^{\infty} \varphi^{\sigma-1} g(\varphi) d \varphi}\right]=\left(\frac{\mathcal{P}}{b}\right)^{\sigma-1} .
$$


Since the left-hand side is monotonically increasing in $\varphi^{* *} / \varphi^{*}$, equation (22) implies an upward sloping relationship between $\varphi^{* *} / \varphi^{*}$ and $\mathcal{P}$. As the relative price of product 2 rises, this reduces demand for product 2 relative to product 1 , inducing consumers to switch from product 2 to product 1 , and leading to a rise in $\varphi^{* *}$ relative to $\varphi^{*}$.

Combining the downward sloping (20) and the upward sloping (22) defines a unique equilibrium pair $\left(\mathcal{P}, \varphi^{* *} / \varphi^{*}\right)$, which satisfies the inequality in equation (21) so that both products are produced. ${ }^{15}$

Starting from equilibrium, if there is a rise in the relative price for product $2, \mathcal{P}$, there are two effects. On the supply side, a rise in $\mathcal{P}$ reduces $\varphi^{* *}$ relative to $\varphi^{*}$, while on the demand side, it increases $\varphi^{* *}$ relative to $\varphi^{*}$. Since relative supply of product 2 has increased and relative demand has fallen, this cannot be an equilibrium and $\mathcal{P}$ must fall in order to bring relative supply and demand back into balance.

\subsection{Free Entry}

The free entry condition FE equating expected firm value and entry costs depends on average profitability in each market, which itself depends on the two productivity cutoffs $\left(\varphi^{*}, \varphi^{* *}\right)$ and relative prices $\mathcal{P}$. Using the relationship between the productivity cutoffs in (20), Appendix B shows that $\mathbf{F E}$ may be written as:

$$
\begin{aligned}
v_{e}= & \frac{f_{1}}{\delta} \int_{\varphi^{*}}^{\Lambda \varphi^{*}}\left[\left(\frac{\varphi}{\varphi^{*}}\right)^{\sigma-1}-1\right] g(\varphi) d \varphi \\
& +\frac{f_{1}}{\delta} \int_{\Lambda \varphi^{*}}^{\infty}\left[\left(\frac{1-a}{a}\right)^{\psi}\left(\frac{1}{b}\right)^{\sigma-1} \mathcal{P}^{\sigma-\psi}\left(\frac{\varphi}{\varphi^{*}}\right)^{\sigma-1}-\frac{f_{2}}{f_{1}}\right] g(\varphi) d \varphi=f_{e} .
\end{aligned}
$$

This provides another equation, which together with (22) and (20), determines unique equilibrium values of three unknowns $\left(\varphi^{*}, \varphi^{* *}, \mathcal{P}\right)$. The equilibrium values $\left(\varphi^{*}, \varphi^{* *}, \mathcal{P}\right)$ are sufficient to determine weighted average productivity and average profitability in each market, as shown in Appen$\operatorname{dix}$ B.

\footnotetext{
${ }^{15}$ See Appendix B for a formal analysis.
} 


\subsection{Goods and Labor Markets}

Total payments to labor used in production equal the difference between total revenue, $R$, and total firm profits, $\Pi: L_{p}=R-\Pi$. Combining $\mathbf{S C}$ and $\mathbf{L M}$, total payments to labor used in entry are exactly equal to total firm profits, $L_{e}=M_{e} f_{e}=\Pi$, reflecting the existence of a competitive fringe of firms entering until the expected value of entry exactly equals the sunk cost. Together, these results imply that total revenue, $R$, equals total payments to labor, $L$, and the labor market clears.

Revenue in each product market may be determined from the CES expenditure share (equation (5)) at equilibrium relative prices: $R_{1}=\alpha_{1}(\mathcal{P}) R$ and $R_{2}=(1-\alpha(\mathcal{P})) R$.

The absolute levels of the price indices, $P_{1}$ and $P_{2}$, in equation (16) depend on the mass of firms producing each product, $M_{1}=\left(R_{1} / \bar{r}_{1}\right)$ and $M_{2}=\left(R_{2} / \bar{r}_{2}\right)$, where aggregate revenue in each product market was determined above and average revenue can be written as a function of the productivity cutoffs and relative prices alone $\left(\varphi^{*}, \varphi^{* *}, \mathcal{P}\right)$.

Proposition 1 There exist unique equilibrium values of $\left\{\varphi^{*}, \varphi^{* *}, P_{1}, P_{2}\right.$, $\left.R_{1}, R_{2}\right\}$ that solve the zero profit, product indifference, free entry, steady-state stability, labor market clearing, and product prices conditions

Proof. See Appendix B

\section{Proposition 2 (Aggregate Variables)}

The equilibrium sextuple $\left\{\varphi^{*}, \varphi^{* *}, P_{1}, P_{2}, R_{1}, R_{2}\right\}$ defines unique equilibrium values of all other endogenous variables of the model $\left\{M_{1}, M_{2}, M_{e}\right.$, $\left.L_{P_{1}}, L_{P_{2}}, L_{e}, C_{1}, C_{2}\right\}$

\section{Proof. See Appendix B}

We have fully characterized the equilibrium sextuple $\left\{\varphi^{*}, \varphi^{* *}, P_{1}, P_{2}\right.$, $\left.R_{1}, R_{2}\right\}$ and solved for the other endogenous variables of the model. The theoretical analysis incorporates endogenous product choice, heterogenous 
firms, heterogeneous products, and industry dynamics in the form of ongoing entry and exit. In equilibrium, firm productivity is correlated with product-level fixed costs, with the most productive firms endogenously choosing to make products with the highest fixed costs.

\section{Market Conditions and Product Choice}

In this section, we examine how changes in market conditions influence firm product choice and result in product switching. Key product characteristics and features of market structure are: the sunk costs of entry $\left(f_{e}\right)$, the fixed costs of production $\left(f_{1}, f_{2}\right)$, the variable cost of production for product 2 relative to that for product $1(b)$, and the demand-shifter $(a)$ capturing the relative weight of the two products in consumers' utility.

Until now we have not restricted the distribution of firm productivity, $g(\varphi)$. In this section we focus on the results assuming that the productivity distribution $g(\varphi)$ is Pareto with parameters $a$ and $k: g(\varphi)=a k^{a} \varphi^{-(a+1)}$, where $k>0, a>0, \varphi \geq k$, and $G(\varphi)=1-\left(\frac{k}{\varphi}\right)^{a} \cdot{ }^{16}$ This assumption simplifies the analysis, as demonstrated in Appendix B, which also contains formal derivations of the comparative statics in this section.

In the interests of brevity, we provide a complete analysis of one aspect of market structure - the sunk costs of entry $\left(f_{e}\right)$. These may be thought of as capturing barriers to entry in the industry, and may be of particular interest in so far as they can be directly influenced by policy. The impact of changes in other market conditions are analogous. We end the section with a more general discussion of how other parameters of the model influence product switching.

As shown in Table 5, an increase in the sunk costs of entry in the industry $\left(f_{e}\right)$ lowers both cutoff productivity levels thus decreasing average productivity in each product and for the industry as a whole. The ratio of the productivity cutoffs, the relative price of the products, the mass of firms producing each product, and average profitability are unchanged. The expected value of entry rises and welfare unambiguously falls.

\footnotetext{
${ }^{16}$ The distribution of within industry (SIC4) cross-firm labor productivity in the US is well-approximated by a Pareto distribution (formally a Pareto-1 distribution). Comparative statics without assuming a particular distribution for firm productivity are available upon request from the authors.
} 
Table 5: Comparative Statics for a Change in the Sunk Cost of Entry

$$
\begin{aligned}
\frac{\partial \varphi^{*}}{\partial f_{e}} & <0 & \frac{\partial \varphi^{* *}}{\partial f_{e}} & <0 \\
\frac{\partial\left(\varphi^{* *} / \varphi^{*}\right)}{\partial f_{e}} & =0 & \frac{\partial \mathcal{P}}{\partial f_{e}} & =0 \\
\frac{\partial \widetilde{\varphi}\left(\varphi^{*}, \varphi^{* *}\right)}{\partial f_{e}} & <0 & \frac{\partial \widetilde{\varphi}\left(\varphi^{*}, \varphi^{* *}\right)}{\partial f_{e}} & <0 \\
\frac{\partial \bar{\pi}_{1}}{\partial f_{e}} & =0 & \frac{\partial M_{1}}{\partial f_{e}} & =0 \\
\frac{\partial \bar{\pi}_{2}}{\partial f_{e}} & =0 & \frac{\partial M_{2}}{\partial f_{e}} & =0 \\
\frac{\partial v_{e}}{\partial f_{e}} & >0 & \frac{\partial W}{\partial f_{e}} & <0
\end{aligned}
$$

As the sunk costs of entry rise above the expected value of entry, a smaller mass of firms, $M_{e}$, will enter the industry. For given values of $\varphi^{*}$ and $\varphi^{* *}$, a smaller mass of entrants implies a smaller mass of firms with productivity realizations high enough to produce in each market. This fall in the mass of firms producing in each market increases ex post profitability.

The increase in ex post profitability means that firms with lower realizations of productivity than before are able to cover the fixed costs of producing product 1 . Hence, in equilibrium the zero profit cutoff productivity $\varphi^{*}$ falls. As $\varphi^{*}$ falls for a given value of $\varphi^{* *}$, this increases the mass of firms in product 1 relative to the mass of firms in product 2 , thereby reducing product 1's relative profitability. Hence, some previously high productivity manufacturers of product 1 now find it more profitable to produce the high fixed cost product 2 and $\varphi^{* *}$ also falls.

The equilibrium ratio of the two productivity cutoffs, $\varphi^{* *} / \varphi^{*}$, is independent of the sunk costs of entry, and hence $\varphi^{* *}$ falls by the same proportion as $\varphi^{*}$. With a Pareto productivity distribution, this leaves the relative price of the two products, $\mathcal{P}$, unchanged.

The fall in both $\varphi^{*}$ and $\varphi^{* *}$ means that some low productivity firms who previously exited now produce product 1 , while some previously high 
productivity manufacturers of product 1 now produce product 2 . For both reasons, weighted average productivity in product $1, \widetilde{\varphi}$, will fall. Similarly, the fall in $\varphi^{* *}$ means that product 2 now includes some lower productivity firms who previously manufactured product 1 . Hence, weighted average productivity in product $2, \widetilde{\widetilde{\varphi}}$, will also fall.

The fall in $\varphi^{*}$ and $\varphi^{* *}$ increases the mass of firms with productivity realizations high enough to produce in each market for a given mass of firms, $M_{e}$, that enter. With a Pareto distribution, this effect exactly offsets the smaller mass of firms entering the industry, so that the mass of firms producing in each product market $\left(M_{1}, M_{2}\right)$ and average ex post profitability $\left(\bar{\pi}_{1}, \bar{\pi}_{2}\right)$ are unchanged.

The expected value of entry, $v_{e}$, rises to equal the new higher sunk costs of entry, $f_{e}$, because the fall in $\varphi^{*}$ and $\varphi^{* *}$ increases the expected probability of a firm having a productivity realization high enough to be able to profitably manufacture either product 1 or product 2 . Welfare per worker, $W$, falls because, although the mass of firms and hence product varieties is unchanged, the fall in average productivity within each product market leads to a rise in average prices.

The effects of changes in other market conditions on product choice are formalized in Appendix B. Increases in the fixed production cost for product $2\left(f_{2}\right)$ reduce relative profitability in this product market, increasing the relative mass of firms that make product 1 , and leading to a rise in $\varphi^{* *} / \varphi^{*}$. Increases in the fixed production cost for product $1\left(f_{1}\right)$ have exactly the opposite effect, increasing the relative mass of firms that make product 2 and reducing $\varphi^{* *} / \varphi^{*}$.

Increases in the variable production cost for product $2(b)$ reduce relative profitability for this product, again increasing the relative mass of firms that make product 1 , and leading to a rise in $\varphi^{* *} / \varphi^{*}$. Increases in the weight of product 1 in consumers' utility $(a)$ raise the relative demand for this product, increasing the relative mass of firms that make product 1 , and again leading to a rise in $\varphi^{* *} / \varphi^{*}$.

In each comparative static, market conditions affect both firms' incentives to enter and exit the market $\left(\varphi^{*}\right)$ and to choose between the two products $\left(\varphi^{* *}\right)$. Changes in product characteristics and market structure result in systematic product switching, with the interaction between firm heterogeneity and product characteristics shaping the pattern of product 
switching. When profitability rises in the market for the high fixed cost product 2 , it is the more productive firms within product product 1 who switch towards this product. Similarly, when profitability rises in the market for the low fixed cost product 1 , it is the less productive firms within product 2 who switch.

\section{Conclusions}

This paper develops a model with endogenous product selection in light of new evidence on the importance of product switching by manufacturing firms. Two thirds of continuing firms change their product mix in any five year period. Multiple-product firms that both drop and add products account for over three quarters of total output. On average, product switches affect more than $40 \%$ of firm output and almost half of existing products. Product additions also involve important changes in the industry composition of the firm, extending the range of industries in more than half of all cases.

Motivated by these stylized facts, the paper develops a theoretical model that integrates endogenous product choice into a dynamic analysis of industry evolution with entry and exit and heterogeneous firms. In equilibrium, firm productivity is correlated with product-level fixed costs, with the most productive firms endogenously choosing to make the products with the highest fixed costs. Changes in market structure result in systematic patterns of firm entry/exit and product switching by continuing firms. For example, increases in an industry's sunk costs of entry make it profitable for less productive firms to survive in the market; result in product switching as the more productive producers of the low fixed cost product 1 switch to the high fixed cost product 2 ; and induce a fall in average productivity within product markets.

The theoretical model introduces endogenous product choice and the possibility of product switching by surviving firms. However, the scope of product switching in the data suggests that future work should allow for firm characteristics, such as productivity, that evolve over time. The addition of shocks to the firm productivity process would provide an additional source of product switching. A multi-industry version of the model would allow for product-switching that changes a firm's industry mix. 
There are a number of theoretical predictions of the current model that are amenable to empirical testing including the response of product switching to changes in market structure such as the sunk cost of entry. A particularly interesting area for further theoretical research is the introduction of international trade. Existing research suggests a number of ways in which firms in developed countries respond to increased globalization: the death of less productive firms; entry into exporting by high productivity firms; and changes in industry composition as more productive firms expand. More recent empirical research has provided evidence of firms switching industry in response to increased competition from low wage countries. This paper suggests that another important margin along which firms may adjust to increased globalization and other changes in the competitive structure of markets is through product choice and/or changes in the nature of the production process. 


\section{References}

Amihud, Y and Baruch, L. (1981) "Risk Reduction as a Managerial Motive for Conglomerate Mergers." Bell Journal of Economics, 12, 605-17.

Bartelsman, Eric and Mark Doms, (2000) "Understanding Productivity: Lessons from Longitudinal Microdata." Journal of Economic Literature, XXXVIII, 569-94.

Bernard, Andrew B. and J. Bradford Jensen, (1995) "Exporters, Jobs, and Wages in US Manufacturing: 1976-87." Brookings Papers on Economic Activity: Microeconomics, 67-112.

Bernard, Andrew B., J. Bradford Jensen and Peter K. Schott. (2002) "Survival of the Best Fit: Competition from Low Wage Countries and the (Uneven) Growth of U.S. Manufacturing Plants." NBER Working Paper \# 9170.

Bernard, Andrew B., Jonathan Eaton, J. Bradford Jensen and Samuel Kortum. (2003) "Plants and Productivity in International Trade." American Economic Review forthcoming.

Bolton, P and Farrell, J. (1990) "Decentralization, Duplication and Delay." Journal of Political Economy, 98, 803-26.

Chamberlin, Edward H. (1951), "Monopolistic Competition Revisited." Economica 18: 343-362.

Chandler, A. (1990) Scale and Scope, Cambridge, MA: Belknap Press.

Davis, Steven J and John Haltiwanger. (1991) "Wage Dispersion between and within U.S. Manufacturing Plants, 1963-86." Brookings Papers on Economic Activity, Microeconomics, pp. 115-80.

Dixit, Avinash K. and Joseph E. Stiglitz. (1977) "Monopolistic Competition and Optimum Product Diversity." American Economic Review, vol. 67, no. 3, 297-308.

Dunne, Timothy, Mark J. Roberts, and Larry Samuelson. (1988) "Patterns of firm entry and exit in U.S. manufacturing industries." Rand Journal of Economics, vol. 19 No.4 Winter, 495-515. 
Dunne, Timothy, Mark J. Roberts, and Larry Samuelson. (1989) "The Growth and Failure of U.S. Manufacturing Plants." Quarterly Journal of Economics, Vol. 104, No. 4 , pp. 671-698.

Gollop, Frank M. and James L. Monahan. (1991) "A Generalized Index of Diversification: Trends in U.S. Manufacturing." Review of Economics and Statistics, 73 , 318-30.

Helfat, Constance E. and Ruth S. Raubitschek. (2000) "Product Sequencing: Co-evolution of Knowledge, Capabilities and Products." Strategic Management Journal, Vol 21: 961-979.

Hopenhayn, Hugo. (1992) "Entry, Exit, and Firm Dynamics in Long Run Equilibrium." Econometrica, 60(5), 1127-1150.

Hotelling, H. (1929) "Stability in Competition." Economic Journal, 39: 41-57.

Krugman, Paul. (1980) "Scale Economies, Product Differentiation, and the Pattern of Trade." American Economic Review, 70, 950-59.

Jovanovic, Boyan. (1982) "Selection and the Evolution of Industry." Econometrica, vol. 50, no. 3, May, 649-70.

Lancaster, Kelvin. (1966), "A New Approach to Consumer Theory." Journal of Political Economy, 74: 132-157.

Melitz, Marc J. (2002) "The Impact of Trade on Intra-Industry Reallocations and Aggregate Industry Productivity." NBER Working Paper \# 8881 .

Milgrom, P and Roberts, J. (1990) "The Economics of Modern Manufacturing: Technology, Strategy and Organization." American Economic Review, 80, 511-28.

Montgomery, C.A. (1994) "Corporate Diversification." Journal of Economic Perspectives, Vol. 8: 1624-1638.

Olley, Steven G. and Ariel Pakes, (1996) "The Dynamics of Productivity in the Telecommunications Equipment Industry." Econometrica, 64(6), 1263-97. 
Shaked, Avner and Sutton, John. (1982) "Imperfect Information, Perceived Quality, and the Formation of Professional Groups." Journal of Economic Theory, vol. 27, no. 1, 170-81

Shaked, Avner and Sutton, John. (1987) "Product Differentiation and Industrial Structure." Journal of Industrial Economics, 36, 131-46.

Spence, A. Michael. (1976) "Product Differentiation and Welfare." American Economic Review, 66:407-414.

Streitwieser, Mary L. (1992) "The Extent and Nature of EstablishmentLevel Diversification in Sixteen U.S. Manufacturing Industries." Journal of Law and Economics, vol. 34, no. 2, Part 2, 503-34 .

Sutton, John. (1998) Technology and Market Structure: Theory and History, MIT Press, Cambridge, Massachusetts.

Tirole, Jean. (1988), The Theory of Industrial Organization, MIT Press, Cambridge, Massachusetts.

U.S. Census Bureau. (1996) "1992 Census of Manufactures: Numerical List of Manufactured and Mineral Products." U.S. Government Printing Office, Washington DC. http://www.census.gov/prod/2/manmin/mc92-r1.pdf

U.S. Census Bureau. (2000) "Bridge Between NAICS and SIC." June, Washington DC. http://www.census.gov/epcd/ec97brdg/97x-cs3.pdf

Yeaple, Stephen R. (2002) "A Simple Model of Firm Heterogeneity, International Trade and Wages." University of Pennsylvania, mimeo. 


\section{A Appendix A: Data}

The data comes from the Censuses of Manufactures (CM) of the Longitudinal Research Database (LRD) of the U.S. Bureau of the Census starting in 1972 and conducted every fifth year through 1997. The sampling unit for the Census is a manufacturing establishment, or plant. Establishments that are not mailed a Census form, so-called 'administrative records (AR)', do not report product-level data. Any firm-year observation that includes an AR establishment is excluded from the sample. Product additions and deletions are recorded only for firms that are present in the sample in neighboring censuses, i.e. we exclude firm births and deaths as well as changes from AR status to regular Census status to focus on product switching at suriving firms. Plant acquisitions and sales by firms will potentially result in changes in product mix, although they account for fewer than $10 \%$ of such switches in the sample.

In Census years, plant output is recorded either at the five-digit or seven-digit SIC level of detail. Roughly 7,000 of the 15,000 seven-digit categories are recorded directly in the LRD, the rest are recorded at a five-digit level of aggregation. We aggregate seven-digit categories up to their five-digit 'product-class' to obtain a comparable level of product detail for all manufacturing firms. A small fraction of firm-product-year observations report negative values for output. We recode these values to zero but leave the products in the firm mix (none of the results are sensitive to this choice).

For the most part, five-digit 1987 SIC categories correspond to products that are likely to be imperfect substitutes and made by different production processes. For example, "Nonferrous Wiredrawing and Insulating" (SIC 3357) includes "Copper Wire", "Power Wire and Cable", and "Fiber Optic Cables". Similarly, "Motor Vehicles" (SIC 3711) contains seven five-digit categories including "Passenger Cars", "Buses", "Combat Vehicles", and four categories of "Trucks" distinguished by weight. Adding or dropping one of these products is likely to entail a substantial change in the production process. The SIC system does not always categorize products into five-digit codes that represent such distinct production processes. "Canned Fruits and Vegetables" (SIC 2033) contains two five-digit products, "Canned Fruits" and "Canned Vegetables, Except Mushrooms". Switches between these products are unlikely to involve 
changes in production technique.

\section{B Appendix B: Theoretical Derivations}

This theoretical appendix contains detailed derivations of key results used in the text and proofs of Propositions.

\section{B1. Product Choice, Ex Ante, and Ex Post Productivity Distributions}

The ex ante distribution of firm productivity prior to entry is $g(\varphi)$. The analysis of product choice in the main text implies that firms' ex ante probability of successful entry is $\left[1-G\left(\varphi^{*}\right)\right]$, where $G(\cdot)$ is the cumulative distribution of $g(\cdot)$. The ex ante probability of producing the low quality good is $\left[G\left(\varphi^{* *}\right)-G\left(\varphi^{*}\right)\right]$, and the ex ante probability of producing the high quality good is $\left[1-G\left(\varphi^{* *}\right)\right]$.

Similarly, the analysis of product choice implies that the ex post distribution of firm productivity for product $1, \mu_{1}(\varphi)$, is the conditional distribution of $g(\varphi)$ on $\left[\varphi^{*}, \varphi^{* *}\right)$,

$$
\mu_{1}(\varphi)=\left\{\begin{array}{cc}
\frac{g(\varphi)}{G\left(\varphi^{* *}\right)-G\left(\varphi^{*}\right)} & \text { if } \varphi^{*} \leq \varphi<\varphi^{* *} \\
0 & \text { otherwise }
\end{array}\right.
$$

while the ex post distribution of firm productivity for product $2, \mu_{2}(\varphi)$, is the conditional distribution of $g(\varphi)$ on $\left[\varphi^{* *}, \infty\right)$,

$$
\mu_{2}(\varphi)=\left\{\begin{array}{cc}
\frac{g(\varphi)}{1-G\left(\varphi^{* *}\right)} & \text { if } \varphi^{* *} \leq \varphi<\infty \\
0 & \text { otherwise }
\end{array}\right.
$$

\section{B2. Aggregate Price Indices}

Equilibrium is characterized by constant masses of firms, $M_{1}$ and $M_{2}$, producing the two products (and hence $M_{1}$ and $M_{2}$ varieties of the products). Aggregate price indices may be written as:

$$
\begin{aligned}
& P_{1}=\left[\int_{0}^{\infty} p_{1}(\varphi)^{1-\sigma} M_{1} \mu_{1}(\varphi) d \varphi\right]^{1 / 1-\sigma} \\
& P_{2}=\left[\int_{0}^{\infty} p_{2}(\varphi)^{1-\sigma} M_{2} \mu_{2}(\varphi) d \varphi\right]^{1 / 1-\sigma} .
\end{aligned}
$$


Using the equilibrium pricing rule (6), the price index for each product may be written as proportional to the price charged by a firm with the (weighted) average productivity of all firms producing that product (equation (16) in the main text). Weighted average productivity is defined as:

$$
\begin{aligned}
& \widetilde{\varphi}\left(\varphi^{*}, \varphi^{* *}\right)=\left[\frac{1}{G\left(\varphi^{* *}\right)-G\left(\varphi^{*}\right)} \int_{\varphi^{*}}^{\varphi^{* *}} \varphi^{\sigma-1} g(\varphi) d \varphi\right]^{1 /(\sigma-1)} \\
& \widetilde{\varphi}\left(\varphi^{*}, \varphi^{* *}\right)=\left[\frac{1}{1-G\left(\varphi^{* *}\right)} \int_{\varphi^{* *}}^{\infty} \varphi^{\sigma-1} g(\varphi) d \varphi\right]^{1 /(\sigma-1)}
\end{aligned}
$$

where $\widetilde{\varphi}(\cdot)$ and $\widetilde{\widetilde{\varphi}}(\cdot)$ are weighted harmonic means of the $\varphi$ 's; the weights reflect relative output shares of firms with different levels of productivities. Note that these weighted averages depend solely on the two cutoff productivities $\left(\varphi^{*}, \varphi^{* *}\right)$ and the ex ante distribution $g(\varphi)$.

\section{B3. Average Profitability}

This section of the appendix establishes two results. First, expected or average profits in each market $\left(\bar{\pi}_{1}, \bar{\pi}_{2}\right)$ are equal to the profits earned by a firm with weighted average productivity $(\widetilde{\varphi}, \widetilde{\widetilde{\varphi}})$. Second, the profits earned by a firm with weighted average productivity may be written as functions of the productivity cutoffs and relative prices $\left(\varphi^{*}, \varphi^{* *}, \mathcal{P}\right)$.

Taking averages in the profit function (7) and using the definitions of weighted average productivity $(\widetilde{\varphi}, \widetilde{\widetilde{\varphi}})$, average profit in each market is equal to the profit of a firm with weighted average productivity:

$$
\bar{\pi}_{1}=\pi_{1}(\widetilde{\varphi}), \quad \bar{\pi}_{2}=\pi_{2}(\widetilde{\widetilde{\varphi}}) .
$$

The relationships between the revenues received by firms with different levels of productivity (equations (8) and (9)) imply that the revenue of a firm with weighted average productivity in each market can be expressed relative to the revenue of a firm with the zero profit cutoff level of productivity $\varphi^{*}$. From the zero profit condition $(\mathbf{Z P})$, the revenue of a firm with the zero profit cutoff level of productivity is proportional to the fixed cost: $r_{1}\left(\varphi^{*}\right)=\sigma f_{1}$ 
Average profit in the two markets is thus equal to:

$$
\begin{aligned}
& \bar{\pi}_{1}\left(\varphi^{*}, \varphi^{* *}\right)=\left[\left(\frac{\widetilde{\varphi}(\cdot)}{\varphi^{*}}\right)^{\sigma-1}-1\right] f_{1} \\
& \bar{\pi}_{2}\left(\varphi^{*}, \varphi^{* *}, \mathcal{P}\right)=\left[\left(\frac{1-a}{a}\right)^{\psi}\left(\frac{1}{b} \frac{\widetilde{\varphi}(\cdot)}{\varphi^{*}}\right)^{\sigma-1} \mathcal{P}^{\sigma-\psi}-\frac{f_{2}}{f_{1}}\right] f_{1}
\end{aligned}
$$

where $(\widetilde{\varphi}, \widetilde{\varphi})$ depend solely on the productivity cutoffs $\left(\varphi^{*}, \varphi^{* *}\right)$, and we have used the expressions for CES expenditure shares, $\alpha_{i}(\mathcal{P})$, in equation (5) to simplify terms.

\section{B4. Product Supply and Relative Prices}

The conditions $\mathbf{Z P}$ and PI imply,

$$
\begin{aligned}
r_{1}\left(\varphi^{*}\right) & =\sigma f_{1} \\
r_{2}\left(\varphi^{* *}\right) & =r_{1}\left(\varphi^{* *}\right)+\sigma\left(f_{2}-f_{1}\right) .
\end{aligned}
$$

The relationship between the revenues received by firms of different productivity in product 1 (equation 8) implies,

$$
\begin{aligned}
& r_{1}\left(\varphi^{* *}\right)=\left(\frac{\varphi^{* *}}{\varphi^{*}}\right)^{\sigma-1} r_{1}\left(\varphi^{*}\right) \\
& r_{2}\left(\varphi^{* *}\right)=\left(\frac{1-a}{a}\right)^{\psi}\left(\frac{1}{b}\right)^{\sigma-1} \mathcal{P}^{\sigma-\psi} r_{1}\left(\varphi^{* *}\right) .
\end{aligned}
$$

Combining these four equations, we obtain equation (20) in the main text.

\section{B5. Product Demand and Relative Prices}

The relative price of product $2, \mathcal{P}$, is the ratio of the price indices in equation (16) and depends on the relative mass of firms producing the two products, $M_{2} / M_{1}$. From the steady-state stability conditions SC, the equilibrium relative mass of firms producing the two products is:

$$
\frac{M_{2}}{M_{1}}=\frac{\left[1-G\left(\varphi^{* *}\right)\right]}{\left[G\left(\varphi^{* *}\right)-G\left(\varphi^{*}\right)\right]} .
$$


Combining this with the definitions of weighted average productivity $(\widetilde{\varphi}, \widetilde{\widetilde{\varphi}})$ in equations (28) and (29), $\mathcal{P}$ may be written as the following function of the productivity cutoffs $\varphi^{* *}$ and $\varphi^{*}$ :

$$
\mathcal{P}=b\left[\frac{\int_{\varphi^{*}}^{\varphi^{* *}} \varphi^{\sigma-1} g(\varphi) d \varphi}{\int_{\varphi^{* *}}^{\infty} \varphi^{\sigma-1} g(\varphi) d \varphi}\right]^{\frac{1}{\sigma-1}}
$$

which is equivalent to equation (22) in the main text.

\section{B6. Combining Product Supply and Product Demand}

It will prove convenient to rearrange the product supply relationship (20) so that $\mathcal{P}$ appears on the left-hand side:

$$
\mathcal{P}=b^{\frac{\sigma-1}{\sigma-\psi}}\left(\frac{a}{1-a}\right)^{\frac{\psi}{\sigma-\psi}}\left[\left(\frac{\varphi^{* *}}{\varphi^{*}}\right)^{1-\sigma}\left(\frac{f_{2}}{f_{1}}-1\right)+1\right]^{\frac{1}{\sigma-\psi}} .
$$

Since $\sigma>1$, the right-hand side is monotonically decreasing in $\varphi^{* *} / \varphi^{*}$ and is graphed in $\left(\mathcal{P}, \varphi^{* *} / \varphi^{*}\right)$ space in Figure 2. $\mathcal{P}$ takes the value $\left(f_{2} / f_{1}\right)^{1 /(\sigma-\psi)}(a /(1-a))^{\psi /(\sigma-\psi)} b^{(\sigma-1) /(\sigma-\psi)}>0$ at $\varphi^{* *} / \varphi^{*}=1$ and converges to a lower value of $(a /(1-a))^{\psi /(\sigma-\psi)} b^{(\sigma-1) /(\sigma-\psi)}>0$ as $\varphi^{* *} / \varphi^{*}$ tends to infinity.

The product demand relationship (22) has already been rearranged so that $\mathcal{P}$ appears on the left-hand side in equation (36) above. The righthand side of equation (36) is monotonically increasing in $\varphi^{* *} / \varphi^{*}$ and is also graphed in $\left(\mathcal{P}, \varphi^{* *} / \varphi^{*}\right)$ space below. As $\varphi^{* *} / \varphi^{*}$ approaches $1, \mathcal{P}$ converges to 0 . As $\varphi^{* *} / \varphi^{*}$ tends to infinity, $\mathcal{P}$ converges to $\infty$.

It follows that there exists a unique equilibrium value of $\varphi^{* *} / \varphi^{*}>1$ where both the product supply and product demand conditions are satisfied, as shown graphically in Figure 2. From the product supply condition, this implies a value for the equilibrium relative price, $\mathcal{P}$, such that the inequality in equation (21) is satisfied and both products are produced.

\section{B\%. Free Entry}

Substitute the expressions for average profit in equations (30) and (31) into the free entry condition FE. Substitute for $\varphi^{* *}$ in FE using (20). 


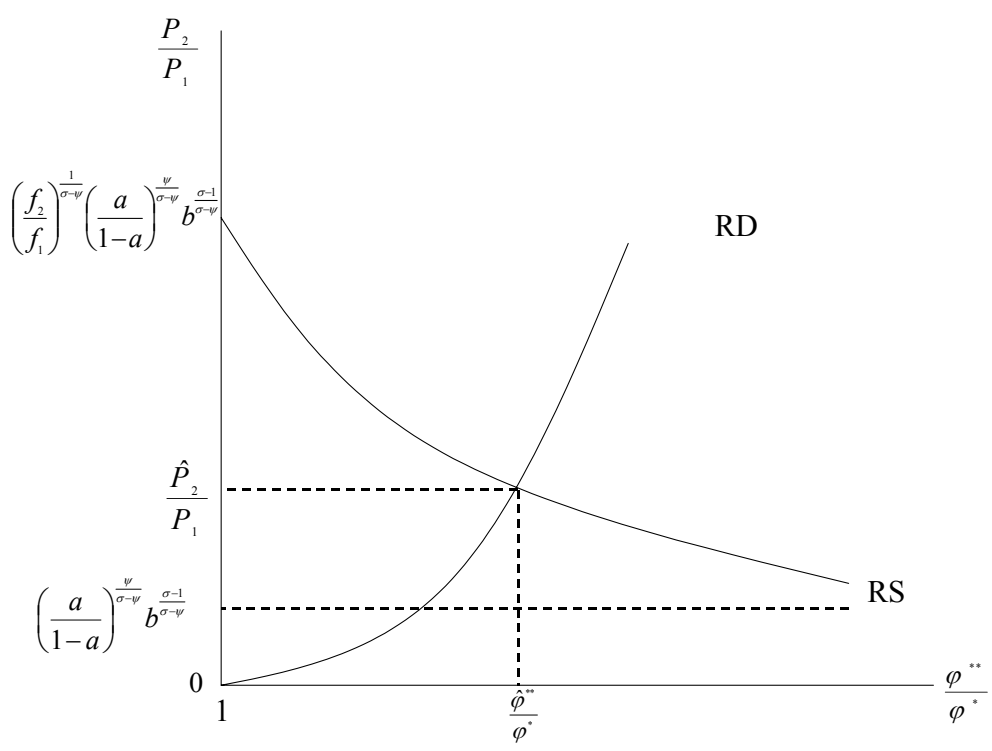

Figure 2: Equilibrium $\mathcal{P}$ and $\varphi^{* *} / \varphi^{*}$

Use the definitions of weighted average productivity $(\widetilde{\varphi}, \widetilde{\varphi})$ in equations (28) and (29) to simplify terms. As a result, FE may be written in terms of $\varphi^{*}, \Lambda \equiv \varphi^{* *} / \varphi^{*}$ and $\mathcal{P}$ as in equation (23) in the main text.

B8. Proof of Proposition 1

Proof. (a) Equations (20) and (22) define unique equilibrium values of $\left(\varphi^{* *} / \varphi^{*}, \mathcal{P}\right)$ as demonstrated in section B6. above. Given values of 
$\Lambda \equiv \varphi^{* *} / \varphi^{*}$ and $\mathcal{P}$, equation (23) is monotonically decreasing in $\varphi^{*}$ :

$$
\begin{gathered}
\frac{d v_{e}}{d \varphi^{*}}<0 \\
\Leftrightarrow \underbrace{\frac{f_{1}}{\delta} \int_{\varphi^{*}}^{\Lambda \varphi^{*}} \varphi^{\sigma-1}(1-\sigma)\left(\varphi^{*}\right)^{-\sigma} g(\varphi) d \varphi}_{\text {Term A }}+\underbrace{\frac{f_{1}}{\delta} \Lambda\left[\Lambda^{\sigma-1}-1\right] g\left(\Lambda \varphi^{*}\right)}_{\text {Term B }} \\
+\underbrace{\frac{f_{1}}{\delta} \int_{\Lambda \varphi^{*}}^{\infty}\left(\frac{1-a}{a}\right)^{\psi}\left(\frac{1}{b}\right)^{\sigma-1} \mathcal{P}^{\sigma-\psi} \varphi^{\sigma-1}(1-\sigma)\left(\varphi^{*}\right)^{-\sigma} g(\varphi) d \varphi}_{\text {Term D }} \\
-\underbrace{\frac{f_{1}}{\delta}\left[\left(\frac{1-a}{a}\right)^{\psi}\left(\frac{1}{b}\right)^{\sigma-1} \mathcal{P}^{\sigma-\psi} \Lambda^{\sigma-1}-\frac{f_{2}}{f_{1}}\right] g\left(\Lambda \varphi^{*}\right)}_{\text {Term C }}<0
\end{gathered}
$$

where the sum of Terms B and D may be written as,

$$
\frac{f_{1}}{\delta} \Lambda g\left(\Lambda \varphi^{*}\right)\left[\left(\frac{f_{2}}{f_{1}}-1\right)-\Lambda^{\sigma-1}\left(\left(\frac{1-a}{a}\right)^{\psi}\left(\frac{1}{b}\right)^{\sigma-1} \mathcal{P}^{\sigma-\psi}-1\right)\right] .
$$

From the definition of $\Lambda$ in equation (20), the term in square parentheses is exactly equal to zero.

Since $\sigma>1$, Terms A and C in equation (38) are negative and $\frac{d v_{e}}{d \varphi^{*}}<0$ for all $\varphi^{*}$. Furthermore, from equation (23), $v_{e} \rightarrow \infty$ as $\varphi^{*} \rightarrow 0$ and $v_{e} \rightarrow 0$ as $\varphi^{*} \rightarrow \infty$.

It follows that, given $\Lambda \equiv \varphi^{* *} / \varphi^{*}$ and $\mathcal{P}$, a unique equilibrium value of $\varphi^{*}$ exists where the expected value of entry, $v_{e}$, is equal to the sunk entry cost, $f_{e}$, and the free entry condition (23) is satisfied.

Thus, together, equations (20), (22) and (23) determine unique equilibrium values of the three unknowns $\left(\varphi^{*}, \varphi^{* *}, \mathcal{P}\right)$.

The equilibrium values of the productivity cutoffs, $\varphi^{*}$ and $\varphi^{* *}$, are sufficient to determine weighted average productivity in each product, $\widetilde{\varphi}$ and $\widetilde{\widetilde{\varphi}}$ (equations $(28)$ and $(29))$ ). Thus, the productivity cutoffs, $\varphi^{*}$ and $\varphi^{* *}$, and relative prices, $\mathcal{P}$, are sufficient to determine average profitability in each product, $\bar{\pi}_{1}$ and $\bar{\pi}_{2}$ (equations (30) and (31)).

(b) Combining the steady-state stability and free entry conditions (SC 
and FE) yields the following relationship between aggregate profitability in the two product markets, $\Pi$, and entry:

$$
M_{e} f_{e}=M_{1} \bar{\pi}_{1}+M_{2} \bar{\pi}_{2}=\Pi .
$$

Since $L_{e}=M_{e} f_{e}=\Pi$ and $L_{p}=R-\Pi$, it follows that $L=L_{p}+L_{e}=R$ and the labor market clears. Revenue in each product market may be determined from the CES expenditure share (equation (5)) at the equilibrium value of relative prices, $\mathcal{P}$, for which we solved above: $R_{1}=\alpha_{1}(\mathcal{P}) L$ and $R_{2}=(1-\alpha(\mathcal{P})) L$.

(c) From the product prices condition $(\mathbf{P P})$ :

$$
\begin{aligned}
& P_{1}=\left(M_{1}\right)^{\frac{1}{1-\sigma}} p_{1}(\widetilde{\varphi})=\left(\frac{\alpha_{1}(\mathcal{P}) L}{\sigma\left(\bar{\pi}_{1}+f_{1}\right)}\right)^{\frac{1}{1-\sigma}} \frac{1}{\rho \widetilde{\varphi}} \\
& P_{2}=\left(M_{2}\right)^{\frac{1}{1-\sigma}} p_{2}(\widetilde{\widetilde{\varphi}})=\left(\frac{\left(1-\alpha_{1}(\mathcal{P})\right) L}{\sigma\left(\bar{\pi}_{2}+f_{2}\right)}\right)^{\frac{1}{1-\sigma}} \frac{1}{\rho \widetilde{\widetilde{\varphi}}}
\end{aligned}
$$

where we have used $M_{i}=R_{i} / \bar{r}_{i}$ for product $i=1,2$, and $\left(\bar{\pi}_{1}, \bar{\pi}_{2}, \widetilde{\varphi}, \widetilde{\widetilde{\varphi}}\right)$ were determined above.

We have thus characterized the equilibrium sextuple $\left\{\varphi^{*}, \varphi^{* *}, P_{1}, P_{2}, R_{1}, R_{2}\right\}$.

\section{B9. Proof of Proposition 2}

Proof. To solve for the equilibrium sextuple $\left\{\varphi^{*}, \varphi^{* *}, P_{1}, P_{2}, R_{1}, R_{2}\right\}$, we used the zero profit, product indifference, free entry, steady-state stability, labor market clearing, and product price conditions.

We now show, using these conditions, that all other endogenous variables of the model may be expressed as functions of the equilibrium sextuple $\left\{\varphi^{*}, \varphi^{* *}, P_{1}, P_{2}, R_{1}, R_{2}\right\}$.

(a) $\left(M_{1}, M_{2}, M_{e}\right)$ : from equation (16), $\left(M_{1}, M_{2}\right)$ can be expressed as functions of the price indices $\left(P_{1}, P_{2}\right)$ and the productivity cutoffs $\left(\varphi^{*}, \varphi^{* *}\right)$. Using equation (39), $M_{e}$ may be expressed as a function of $\left(M_{1}, M_{2}\right)$ and $\left(\bar{\pi}_{1}, \bar{\pi}_{2}\right)$, where average profitability may be written as a function of $\left(\varphi^{*}\right.$, $\left.\varphi^{* *}, \mathcal{P}\right)$ alone.

(b) Total payments to labor used in production in each market $i$ equal the 
difference between revenue, $R_{i}$, and total firm profits, $\Pi_{i}$, in that market:

$$
\begin{aligned}
& L_{p 1}=R_{1}-\Pi_{1}=R_{1}-\left(M_{1} \bar{\pi}_{1}\right) \\
& L_{p 2}=R_{2}-\Pi_{2}=R_{2}-\left(M_{2} \bar{\pi}_{2}\right)
\end{aligned}
$$

where we have used the choice of labor as numeraire; $\left(M_{1}, M_{2}\right)$ can be expressed as functions of the price indices $\left(P_{1}, P_{2}\right)$ and the productivity cutoffs $\left(\varphi^{*}, \varphi^{* *}\right) ; \bar{\pi}_{1}$ and $\bar{\pi}_{2}$ are functions of $\left(\varphi^{*}, \varphi^{* *}, \mathcal{P}\right)$ alone. Payments to labor used in entry are:

$$
L_{e}=M_{e} f_{e}
$$

where $M_{e}$ was determined above.

(c) The first-order conditions for consumer optimization imply:

$C_{1}=R \frac{a^{\psi} P_{1}^{-\psi}}{\left[a^{\psi} P_{1}^{1-\psi}+(1-a)^{\psi} P_{2}^{1-\psi}\right]}, \quad C_{2}=R \frac{(1-a)^{\psi} P_{2}^{-\psi}}{\left[a^{\psi} P_{1}^{1-\psi}+(1-a)^{\psi} P_{2}^{1-\psi}\right]}$

where, from the proof of Proposition $1, R=L$.

\section{B10. Market Structure and Product Choice}

\section{B10.1. Pareto Distribution}

We begin by developing some properties of the model when productivity is Pareto distributed. Suppose that $g(\varphi)$ is Pareto- 1 with parameters $a$ and $k: g(\varphi)=a k^{a} \varphi^{-(a+1)}$ where $k>0, a>0$, and $\varphi \geq k$. The cumulative distribution function for productivity becomes $G(\varphi)=1-\left(\frac{k}{\varphi}\right)^{a}$.

Assuming $a>\sigma-1$, the term $\varphi^{\sigma-1} g(\varphi)$ also follows a Pareto distribution with parameters $\gamma \equiv a-\sigma+1$ and $k$,

$$
\begin{gathered}
\varphi^{\sigma-1} g(\varphi)=\xi h(\varphi) \\
\text { where } \quad h(\varphi)=\gamma k^{\gamma} \varphi^{-(\gamma+1)}, \quad k>0, \gamma>0, \varphi \geq k \\
H(\varphi) \equiv \int_{0}^{\varphi} h(\varphi) d \varphi=\left[1-\left(\frac{k}{\varphi}\right)^{\gamma}\right] \\
\xi \equiv a k^{a-\gamma} / \gamma>0
\end{gathered}
$$


This property substantially simplifies the expressions for average productivity, average profitability, and the aggregate price indices derived above, all of which contain the term $\varphi^{\sigma-1} g(\varphi)$.

Using this result in equation (22), the product demand relationship between the productivity cutoffs $\left(\varphi^{*}, \varphi^{* *}\right)$ and relative prices $(\mathcal{P})$ simplifies to:

$$
\mathcal{P}=b\left[\left(\varphi^{* *} / \varphi^{*}\right)^{\gamma}-1\right]^{1 / \sigma-1} .
$$

Combining this with the product supply relationship in equation (20), we are able to derive an explicit expression for the equilibrium value of $\varphi^{* *} / \varphi^{*}$ as a function of the parameters of the model:

$$
\left[\left(\frac{\varphi^{* *}}{\varphi^{*}}\right)^{\gamma}-1\right]^{\frac{1}{\sigma-1}}=\left[\left(\frac{\varphi^{* *}}{\varphi^{*}}\right)^{1-\sigma}\left(\frac{f_{2}}{f_{1}}-1\right)+1\right]^{\frac{1}{\sigma-\psi}}\left(\frac{a}{1-a}\right)^{\frac{\psi}{\sigma-\psi}} b^{\frac{\psi-1}{\sigma-\psi}}(4
$$

where the left-hand side is monotonically increasing and the right-hand side monotonically decreasing in $\varphi^{* *} / \varphi^{*}$. Noting this, and taking limits of the left and right-hand side as $\varphi^{* *} / \varphi^{*} \rightarrow 1$ and $\varphi^{* *} / \varphi^{*} \rightarrow \infty$, it follows that a unique equilibrium value of $\varphi^{* *} / \varphi^{*}$ exists.

It is straightforward to undertake comparative statics using equation (41). A rise in the product 2 fixed production cost, $f_{2}$, increases the righthand side, leading to a higher equilibrium $\varphi^{* *} / \varphi^{*}$ and a fall in the relative mass of firms making product 2. A rise in the product 1 fixed production cost, $f_{1}$, reduces the right-hand side, leading to a lower equilibrium $\varphi^{* *} / \varphi^{*}$ and a rise in the relative mass of firms making product 2 .

An increase in the weight of product 1 in consumers' utility function, $a$, increases the right-hand side, leading to a higher equilibrium $\varphi^{* *} / \varphi^{*}$ and a fall in the relative mass of firms making product 2 . An increase in the relative variable production cost for product $2, b$, also increases the righthand side, leading to a higher equilibrium $\varphi^{* *} / \varphi^{*}$ and a fall in the relative mass of firms making product 2 .

\section{B10.2. Sunk Cost of Entry $\left(f_{e}\right)$ Comparative Statics}

From $\mathbf{F E}$, an increase in the sunk costs of entry $f_{e}$ requires a corresponding increase in the expected value of entry $v_{e}$. The expected value of entry 
may be written as equation (23), where, from equation (20), $\varphi^{* *} / \varphi^{*}=\Lambda$ is independent of the sunk costs of entry $f_{e}$.

The expected value of entry in (23) is monotonically decreasing in the zero-profit cutoff productivity $\varphi^{*}$. Therefore, as the sunk costs of entry rise, the zero-profit cutoff productivity $\varphi^{*}$ must fall so as to increase the expected value of entry equal to the new higher sunk cost.

Since $\varphi^{* *}=\Lambda \varphi^{*}$ and $\Lambda$ is unchanged, $\varphi^{* *}$ will also fall by the same proportion. Hence, we have established: $\partial \varphi^{*} / \partial f_{e}<0, \partial \varphi^{* *} / \partial f_{e}<0$ and $\partial\left(\varphi^{* *} / \varphi^{*}\right) / \partial f_{e}=0$. With a Pareto productivity distribution, the relative price, $\mathcal{P}$, depends solely on $\varphi^{* *} / \varphi^{*}$ and hence $\partial \mathcal{P} / \partial f_{e}=0$.

From the definition of weighted average productivities, $\widetilde{\varphi}$ and $\widetilde{\varphi}$, in equations (28) and (29) and from the analysis of the Pareto distribution in section B10.1.:

$$
\begin{aligned}
{\left[\widetilde{\varphi}\left(\varphi^{*}, \varphi^{* *}\right)\right]^{\sigma-1} } & =\frac{H\left(\varphi^{* *}\right)-H\left(\varphi^{*}\right)}{G\left(\varphi^{* *}\right)-G\left(\varphi^{*}\right)} \\
& =\left(\varphi^{*}\right)^{\sigma-1} \xi\left[\frac{k^{\gamma}-\left(\frac{k}{\Lambda}\right)^{\gamma}}{k^{a}-\left(\frac{k}{\Lambda}\right)^{a}}\right] \\
{\left[\widetilde{\varphi}\left(\varphi^{*}, \varphi^{* *}\right)\right]^{\sigma-1} } & =\frac{1-H\left(\varphi^{* *}\right)}{1-G\left(\varphi^{* *}\right)} \\
& =\left(\varphi^{* *}\right)^{\sigma-1} k^{1-\sigma} .
\end{aligned}
$$

Since $\sigma>1$, it follows that $d \widetilde{\varphi} / d \varphi^{*}>0$ and hence $d \widetilde{\varphi} / d f_{e}=\left(d \widetilde{\varphi} / d \varphi^{*}\right)\left(d \varphi^{*} / d f_{e}\right)<$ 0 . Similarly, $d \widetilde{\varphi} / d \varphi^{* *}>0$ and hence $d \widetilde{\varphi} / d f_{e}=\left(d \widetilde{\widetilde{\varphi}} / d \varphi^{* *}\right)\left(d \varphi^{* *} / d f_{e}\right)<0$.

The change in average profitability in equations (30) and (31) depends upon the change in the ratios of weighted average productivity, $\widetilde{\varphi}$ and $\widetilde{\widetilde{\varphi}}$, to the zero profit cutoff level of productivity, $\varphi^{*}$ :

$$
\begin{aligned}
\left(\frac{\widetilde{\varphi}\left(\varphi^{*}, \varphi^{* *}\right)}{\varphi^{*}}\right)^{\sigma-1} & =\frac{1}{\left(\varphi^{*}\right)^{\sigma-1}}\left[\frac{H\left(\varphi^{* *}\right)-H\left(\varphi^{*}\right)}{G\left(\varphi^{* *}\right)-G\left(\varphi^{*}\right)}\right] \\
& =\xi\left[\frac{k^{\gamma}-\left(\frac{k}{\Lambda}\right)^{\gamma}}{k^{a}-\left(\frac{k}{\Lambda}\right)^{a}}\right]
\end{aligned}
$$




$$
\begin{aligned}
\left(\frac{\widetilde{\widetilde{\varphi}}\left(\varphi^{*}, \varphi^{* *}\right)}{\varphi^{*}}\right)^{\sigma-1} & =\frac{1}{\left(\varphi^{*}\right)^{\sigma-1}}\left[\frac{1-H\left(\varphi^{* *}\right)}{1-G\left(\varphi^{* *}\right)}\right] \\
& =\Lambda^{\sigma-1} \xi k^{1-\sigma} .
\end{aligned}
$$

From the above, it is clear that, with $\Lambda$ unchanged, $\partial \bar{\pi}_{1} / \partial \varphi^{*}=\partial \bar{\pi}_{1} / \partial \varphi^{* *}=$ 0 and $\partial \bar{\pi}_{2} / \partial \varphi^{*}=\partial \bar{\pi}_{2} / \partial \varphi^{* *}=0$. Hence, $\partial \bar{\pi}_{1} / \partial f_{e}=0$ and $\partial \bar{\pi}_{2} / \partial f_{e}=0$. The mass of firms producing each product is:

$$
\begin{aligned}
& M_{1}=\frac{R_{1}}{\bar{r}_{1}}=\frac{\alpha_{1}(\mathcal{P}) L}{\sigma\left(\bar{\pi}_{1}+f_{1}\right)} \\
& M_{2}=\frac{R_{2}}{\bar{r}_{2}}=\frac{\left(1-\alpha_{1}(\mathcal{P})\right) L}{\sigma\left(\bar{\pi}_{2}+f_{2}\right)} .
\end{aligned}
$$

Since both relative prices, $\mathcal{P}$, and relative profitability, $\bar{\pi}_{1}$ and $\bar{\pi}_{2}$, are unchanged: $\partial M_{1} / \partial f_{e}=0$ and $\partial M_{2} / \partial f_{e}=0$. Welfare per worker is:

$$
\begin{aligned}
& W=\left[a^{\psi} P_{1}^{1-\psi}+(1-a)^{\psi} P_{2}^{1-\psi}\right]^{\frac{1}{\psi-1}} \\
& P_{1}=\left(\frac{R_{1}}{\bar{r}_{1}}\right)^{\frac{1}{1-\sigma}} p_{1}(\widetilde{\varphi})=\frac{\alpha_{1}(\mathcal{P}) L}{\sigma\left(\bar{\pi}_{1}+f_{1}\right)} \frac{1}{\rho \widetilde{\varphi}} \\
& P_{2}=\left(\frac{R_{2}}{\bar{r}_{2}}\right)^{\frac{1}{1-\sigma}} p_{2}(\widetilde{\widetilde{\varphi}})=\frac{\left(1-\alpha_{1}(\mathcal{P})\right) L}{\sigma\left(\bar{\pi}_{2}+f_{2}\right)} \frac{b}{\rho \widetilde{\varphi}} .
\end{aligned}
$$

Average profitability in each market, $\bar{\pi}_{1}$ and $\bar{\pi}_{2}$, is unchanged, while average productivity, $\widetilde{\varphi}$ and $\widetilde{\widetilde{\varphi}}$, has fallen. Hence, the rise in the sunk cost of entry leads to an increase in the price indices, $P_{1}$ and $P_{2}$, and a fall in welfare per worker, $W$. 


\section{CENTRE FOR ECONOMIC PERFORMANCE \\ Recent Discussion Papers}

593 Anthony J. Venables

592 Sylvie Charlot Gilles Duranton

591 Paul Willman

Alex Bryson

Rafael Gomez

590 Marco Manacorda

589 Alex Bryson Rafael Gomez

588 Henry G. Overman L. Alan Winters

587 Pierre-Philippe Combes Henry G. Overman

586 Henry G. Overman

585 A. B. Bernard

J. Bradford Jensen

P. K. Schott

584 A. B. Bernard

J. Bradford Jensen

P. K. Schott

583 S. Wood

S. Moore

582 T. Kirchmaier

581
Spatial Disparities in Developing Countries: Cities, Regions and International Trade

Communication Externalities in Cities

Why Do Voice Regimes Differ?

Childcare and the Labour Supply of Other Household Members: Evidence from 1920s America

Why Have Workers Stopped Joining Unions?

Trade Shocks and Industrial Location: the Impact of EEC Accession on the UK

The Spatial Distribution of Economic Activities in the European Union

Can We Learn Anything from Economic Geography Proper?

Falling Trade Costs, Heterogeneous Firms and Industry Dynamics

Survival of the Best Fit: Exposure to Low-Wage Countries and the (Uneven) Growth of U.S.

Manufacturing Plants

Reviewing the Statutory Union Recognition (ERA 1999)

Corporate Restructuring and Firm Performance of British and German Non-Financial Firms

Why Is the Rate of Return to Schooling Higher for Women than for Men? 
$580 \quad$ S. Burgess

D. Mawson

579 S. Nickell

578 D. Marsden

$577 \quad$ S. Nickell

576 A. de Coulon

M. Piracha

575 H. Steedman

K. Wagner

J. Foreman

574 S. Gibbons

573 R. Griffith

S. Redding

H. Simpson

572 S. Redding

P. K. Schott

571 B. Petrongolo

C. A. Pissarides

570 M. Coles

B. Petrongolo

569 A. Bryson

L. Cappellari

C. Lucifora

568 A. Bryson

R. Gomez
Aggregate Growth and the Efficiency of Labour

Reallocation

Poverty and Worklessness in Britain

Renegotiating Performance: the Role of Performance

Pay in Renegotiating the Effort Bargain

A Picture of European Unemployment: Success and Failure

Self-Selection and the Performance of Return

Migrants: the Source Country Perspective

The Impact on Firms of ICT Skill-Supply Strategies:

An Anglo-German Comparison

The Costs of Urban Property Crime

Productivity Convergence and Foreign Ownership at the Establishment Level

Distance, Skill Deepening and Development: Will Peripheral Countries Ever Get Rich?

Scale Effects in Markets with Search

A Test Between Unemployment Theories Using Matching Data

Does Union Membership Really Reduce Job

Satisfaction?

Segmentation, Switching Costs and the Demand for Unionization in Britain 